\title{
Designing Sentence Templates in Computer-Supported Collaborative Learning
}

\author{
Hyejeong Lee and Dongsik Kim
}

\begin{abstract}
Communication activities play a critical role to build constructed knowledge in collaborative learning situation. Learners can have effective communication not only by actively participating in discussion but also by presenting the ideas clearly. Argumentation is a clear and logical ways to express one's opinion. Sentence openers were exploited in several studies to support learner's argumentation. Sentence openers are the pre-defined ways to start a sentence, for example, I think..., I agree with your idea... etc. However, those sentence openers only focused on how to start a sentence. It does not have to do with how to make proper sequence of sentences. Thus, based on Toulmin's argument model, we extend the sentence openers and propose sentence template which is combination of sentence opener and writing template to foster learners' argumentative knowledge and to enhance the quality of argument, therefore reaching a fruitful shared understanding.
\end{abstract}

Index Terms-Computer-supported collaborative learning, sentence template, argumentation knowledge, shared understanding.

\section{INTRODUCTION}

CSCL refers to computer-supported collaborative learning which focuses on a collaborative activity among peers supported by technology. CSCL could be seen as a meaningful learning environment in that the environment affords learners to interact, share and negotiate their ideas and construct the higher level of joint knowledge [1].

Communication activities in the CSCL play a critical role to share their knowledge among participants in collaborative learning situation. From this line of thought, it was assumed that collaborative learning will be enhanced if students participate in discussion actively. However, the research results suggest that the effects of active communication were rather inconclusive [2]. Positive effect of learning outcomes from the notion was not always guaranteed even if students communicate actively. In order to maintain effective communication activities, other aspects of communication process, such as the quality of discussion, should be considered as well.

Collaborative learning may require learners to engage in argumentation activity [3]. During the collaboration, learners often use arguments to represent their opinion of the problem and persuade others to agree and accept their opinion.

Manuscript received September 28, 2012; revised January 13, 2013.

Hyejeong Lee is with the Department of Educational Technology from Hanyang University, Seoul, Korea (e-mail: gogolhj@ gmail.com).

Dongsik Kim is with the Department of Educational Technology in Hanyang University, Seoul, Korea (e-mail: kimdsik@hanyang.ac.kr).
Argumentation is conceived as a means for constructing shared understanding [4] because the logical way of expression helps learners to understand each other more effectively. However, learners who have little experience on collaborative learning do not know how to argue each other, consequently they may have trouble to produce efficient discussion, and fail to reach a shared understanding on assigned learning topics [5].

To support argumentative activity in a computer-mediated environment, different ways of scaffolds have been provided: structured interface [3], visual representation system [6], [7], guideline, etc.

In this study, sentence template is designed and proposed to facilitate learners' communication activities as well as and to enhance the quality of argument.

\section{KNOWLEDGE ACQUISITION AND CONSTRUCTION}

\section{A. Argumentative Knowledge Acquisition}

Kuhn defines the skills of argument is the ability to reason for the claim, generate counter-argument, to response against counter-argument, and so forth [8]. While argumentative skills stress the ability to construct strong argument argumentative knowledge refers to know which concepts to use to solve problems (the epistemic dimension), what consists of coherent argument (the argument dimension), and how to interact with other leaners (the dimension of social modes of co-construction) [3]. Usually skills cannot be acquired in short period of time and hard to teach. For novice learners who even does not know how to differentiate the claim and the evidence, argumentative knowledge acquisition should be preceded before concerning the obtaining of argument skills. Argumentative knowledge can be taught through collaboration scripts or scaffolds.

\section{B. Domain-Specific Knowledge Construction}

The meta-analysis results on the domain-specific knowledge in CSCL suggests that argumentation can be a medium for gaining domain-specific knowledge [9]. To explain how argumentation works for construction of domain-specific knowledge within groups, Fig. 1 represents the process of unshared individual knowledge becomes group's constructed knowledge through externalization, internalization, negotiation and integration [10].

Argumentation is a powerful way to express participants' thoughts and justify the assertions by providing evidences which support the individual's propositions. One person makes a claim with supporting evidence, which is only stored in the individual's memory. It can be considered an externalization. And other members of the group try to 
understand the assumption and the claim, which is internalization. It does not mean that all other members of the group decide to accept the claim even if they have shared knowledge. They have to negotiate each other to reach a same understanding, which is common ground. So, sometimes more than one single argument is needed. Finally constructed knowledge is built upon common ground as they integrate the common knowledge into individual cognitive system. Through this interaction process, unshared knowledge becomes constructed knowledge. Participants can construct domain-specific knowledge by engaging the collaborative learning with argumentation.

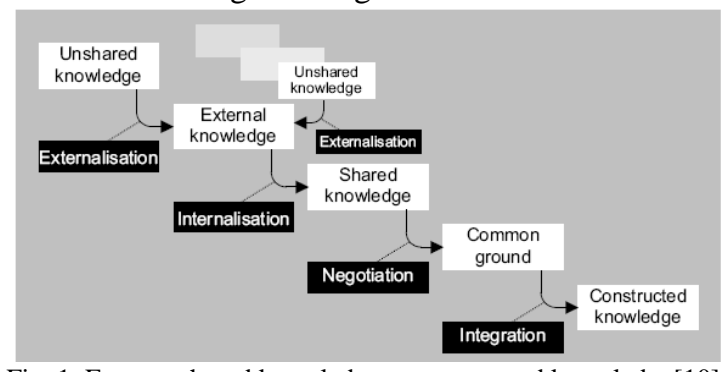

Fig. 1. From unshared knowledge to constructed knowledge[10]

\section{STRUCTURING DiscourSES}

\section{A. Structured Interface}

The purpose of CSCL is to support learners to work together effectively with technology [11]. Effective collaboration could not be easily produced without providing well-structured interaction guidance[5]. Structured dialogue interfaces provide restricted discourse interactions that learners can use to compose their communication [12]. Structured interaction prompts the generation of coherent arguments [13], task-oriented discourse and reflective activity [14].

Sentence openers were included in structuring software system to encourage learners to engage in collaborative interaction, and the empirical evidences showed that using sentence openers promote positive communication activity. [14]-[16].

\section{B. Sentence Opener}

Sentence opener is a set of compound words that offers the pre-defined ways to start a sentence [17]. It structures the interactions by providing learners an opportunity to choose one of given communicative possibilities [14]. Students choose a sentence opener before typing reminder of sentence and complete sentence with it. For example, if a student decides to use a sentence opener "In my opinion", the student will only need to write additional text, like "children should listen to their parents before making a decision".

There were some advantages of using sentence openers in argumentative activity: providing possibilities to start the writing process; making learners pause and think; helping to communicate more explicitly; promoting in-depth arguments, reflecting upon etc [18].

\section{Sentence Template}

We may argue that whether learners really benefit from sentence openers for their argumentative construction. It seems difficult to support argumentative construction simply

with sentence openers, because Sentence openers only focus on how to start a sentence and do not have to do with how to make proper sequences of sentences or relationships between the claim and the ground. Sentence openers are more suitable for synchronous chatting environment. Table I shows most sentence openers are embedded in synchronous environment. However, argumentation writing activity requires some extent of time to complete and thus, an asynchronous communication device should be provided and sentence template is more suitable for that purpose.

TABLE I: CATEGORIES OF SENTENCE OPENERS

\begin{tabular}{lll}
\hline \hline & $\begin{array}{l}\text { CSCL } \\
\text { environment }\end{array}$ & Categories of sentence opener \\
\hline Baker \& Lund, & C-CHENE & Organized by communicative \\
(synchronous) & act & $\begin{array}{l}\text { 1. Construct the chain } \\
\text { (task-oriented) }\end{array}$ \\
& & 2. Come to agreement \\
& 3. Manage the interaction \\
& 4. Do something else \\
& & \\
& & Organized by speech act types \\
ICLS & 1. Request \\
& 2. Inform \\
& 3. Motivate \\
& 4. Maintenance \\
& 5. Task \\
& 6. Acknowledge \\
& 7. Argue \\
& 8. Mediate
\end{tabular}

Robertson et al. 1998[15]

Lazonder et al., 2003[17]

McAlister et al., 2004[19] Hirsch et al.,
2004[20]

Yiong-Hwee \& Churchill, 2007[18]
BetterBlether (synchronous)

Co-Lab chat (synchronous)

AcademicTalk (synchronous)

ALEX (synchronous)

Knowledge Community (asynchronous)
Organized by discussion skills The names of the categories are not stated, but sentence openers are grouped by discussion skills such as communication skills, task skills, creative conflict skills etc.

\section{Organized by communicative function \\ 1. Give information \\ 2. Give an argument \\ 3. Make a proposal \\ 4. Ask a question \\ 5. Ask for practical matters}

\section{Organized by intention \\ 1. Inform \\ 2. Question \\ 3. Challenge}

Organized by regular pattern

1. Basic(opinion)

2. Explore

3. Question

4. Dialogue

\section{Organized by Socratic thinking and reasoning \\ 1. Probe Reasons \\ 2. Probe Veiwpoints \\ 3. Probe Assumptious \\ 4. Probe Implications \& Consequences \\ 5. Probe Clarification \\ 6. Take a Stand}


Based on Toulmin's argument model[21], we extend the sentence opener and propose sentence template which is combination of sentence opener and writing template.

In this study, the aim of providing sentence template in argumentative activity is not to formulate general structures of learners' essays or writings, but rather to foster learners' argumentative knowledge.

\section{DESIGN PRINCIPLES OF SENTENCE TEMPLATE}

\section{A. Toulmin's Argument Model}

In previous studies, sentence openers were grouped and organized in different ways (See Table II). In this study, our sentence template is organized based on Toulmin's argument model, as shown in Fig. 2. Toulmin's model has been widely used in computer-supported collaborative learning[3], [22], [23]. According to Toulmin's layout of argument, there are five components: claim, data, warrant, backing, qualifier and rebuttal. The claim is what the speaker wants to assert. The conclusion is actually same with the claim. To make the claim reasonable and valid and ultimately become the conclusion, we need to establish grounds which support for the claim. The data gives the supported information to the claim. The warrant explains how the data is connected to the claim and the backing backs up the warrant. The qualifier specifies the different degrees of certainty on claim. And rebuttal describes the exceptions to the claim.

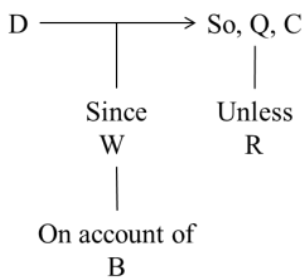

Fig. 2. The structure of Toulmin's argument model.

\section{B. Micro Argument}

A micro argument is an abstract model of Toulmin's argument model. It is developed in one claim and two or three grounds. Grounds contains data, warrant and backing [22]. Since proposed sentence templates are targeted to inexperienced learner in collaborative argumentation, micro argument only includes the claim and the ground rather than includes all components of argument (claim, data, warrant, backing, and qualifier)

\section{Flexibility: The Freedom of the Use}

In the study of CSCL, the computer-mediated learning environment using sentence opener is considered as flexible structure [14] or semi-structured [17] since it did not force learners to select and use it all the time for their communication during collaborative learning with peers.

\section{Domain-General Pattern}

With consideration for the efficiency of use, our sentence templates are developed in domain-general pattern; thus these sentence templates can occur regardless of the specific domain.

\section{E. Asynchronous Discourse}

An asynchronous communicative environment provides less pressure to communicate immediately [17]. Asking delayed ideas encourages deep and critical thinking [24].

Argumentative writing requires some extent of time to complete and thus, an asynchronous communication environment will be offered with sentence templates rather than synchronous environment.

TABLE II: SENTENCE TEMPLATES

\begin{tabular}{|c|c|}
\hline Label & Sentence openers \\
\hline Claim & $\begin{array}{l}\text { When it comes to the issue of .... I agree/I don't agree } \\
\text { In discussion of... I think/ } \\
\text { With regard to... I am of the opinion that } \\
\text { None }\end{array}$ \\
\hline Ground1 & $\begin{array}{l}\text { Firstly, it is because } \\
\text { According to } \\
\text { The indicator supporting my opinion are } \\
\text { None }\end{array}$ \\
\hline Ground2 & $\begin{array}{l}\text { Secondly, it is because } \\
\text { In addition, } \\
\text { Furthermore, } \\
\text { None }\end{array}$ \\
\hline Ground3 & $\begin{array}{l}\text { Finally, } \\
\text { Last but not least, } \\
\text { None }\end{array}$ \\
\hline Conclusion & $\begin{array}{l}\text { In sum, } \\
\text { In conclusion, } \\
\text { None }\end{array}$ \\
\hline
\end{tabular}

\section{A SKetch OF SENTENCE TEMPlates}

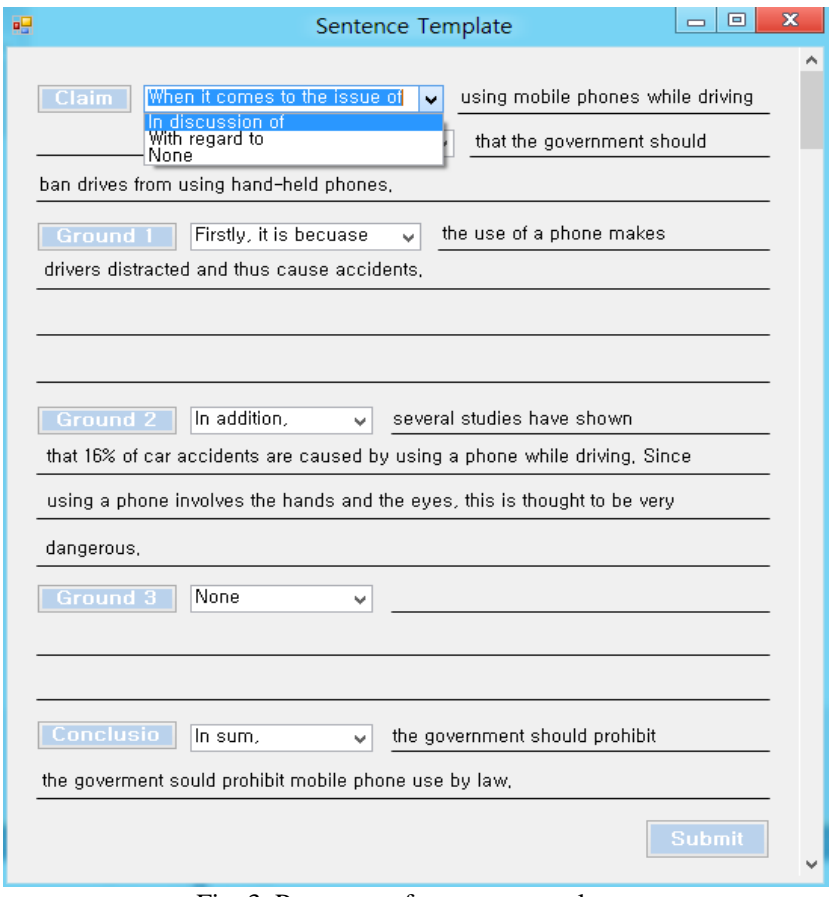

Fig. 3. Prototype of sentence templates.

There are five categorized pull-down lists (five categories: Claim, Ground1, Ground2, Groud3, and Conclusion). It does not change and is common to all students. Clicking on one of the lists reveals all sentence templates in that group, as shown in Fig. 3. Students must choose one of sentence templates and compose their sentences and writing. There is 'None' in each 
category which means that students are remained free to start their sentences without the sentence templates which already determined and presented in a category. When done, students should press the submit button. The written sentences they already filled in with sentence templates will be one single argument.

\section{CONCLUSION}

By argumentative knowledge it is referred to the ability to make a cogent and strong relationship between claim and conclusion. Sentence templates will help learners develop logical and persuasive argumentation because it gives the space to the learners to think logically and write topic-focused argument. With this help, students will eventually build argumentative knowledge.

Shared understanding and domain-specific knowledge construction can be occurred through the effective communication. Through argumentation, the reasons and evidences supporting for the learner's claim will make the peer understand the learner's opinion easily and effectively. Consequently, they can reach shared understanding.

We expect that our proposed sentence template can foster learner's argumentative knowledge by providing them how to sequence all sentences, thus improve the quality of discussion and help reach shared understanding among peers and integrate constructed knowledge into their own cognitive memory.

\section{REFERENCES}

[1] L. Lipponen, "Exploring foundations for computer-supported collaborative learning," in Proc. the Conference on Computer Support for Collaborative Learning: Foundations for a CSCL Community, 2002, pp. 72-81

[2] S. Järvelä and P. Häkkinen, "Web-based cases in teaching and learning-the quality of discussions and a stage of perspective taking in asynchronous communication," Interactive Learning Environments, vol. 10 , pp. 1-22, 2002

[3] A. Weinberger, K. Stegmann, F. Fischer, and H. Mandl, "Scripting Argumentative Knowledge Construction in Computer-Supported Learning Environments," in F. Fischer, I. Kollar, H. Mandl, and J. M. Haake, Eds., Scripting Computer-Supported Collaborative Learning. vol. 6, Springer US, 2007, pp. 191-211.

[4] B. B. Schwarz, "Argumentation and learning," Argumentation and Education, pp. 91-126, 2009

[5] A. King, "Scripting collaborative learning processes: A cognitive perspective," Scripting computer-supported collaborative learning, pp. 13-37, 2007

[6] M. van Amelsvoort, J. Andriessen, and G. Kanselaar, "Representational tools in computer-supported collaborative argumentation-based learning: How dyads work with constructed and inspected argumentative diagrams," The Journal of the Learning Sciences, vol. 16, pp. 485-521, 2007.

[7] B. B. Schwarz, Y. Neuman, J. Gil, and M. Ilya, "Construction of collective and individual knowledge in argumentative activity," The Journal of the Learning Sciences, vol. 12, pp. 219-256, 2003.

[8] D. Kuhn, The skills of argument: Cambridge University Press, 1991.

[9] C. Wecker and F. Fisher, "The Role of Argumentation for Domain-Specific Knowledge Gains In Computer-Supported Collaborative Learning: A Meta-Analysis," in Proc. the 9th conference on Computer-supported collaborative learning, Hong Kong, China, 2011, pp. 304-311.

[10] P. J. Beers, P. A. Kirschner, H. Boshuizen, and W. H. Gijselaers, "Coercing knowledge construction in collaborative learning environments," in Proc. the 2005 conference on Computer support for collaborative learning: learning 2005: the next 10 years!, 2005, pp. 8-17.

[11] S. Järvelä, P. Häkkinen, M. Arvaja, and P. Leinonen, "Instructional support in CSCL," What we know about CSCL, pp. 115-139, 2004.

[12] P. Jermann, A. Soller, and A. Lesgold, "Computer software support for CSCL," What we know about CSCL, pp. 141-166, 2004.

[13] K. L. Cho and D. H. Jonassen, "The effects of argumentation scaffolds on argumentation and problem solving," Educational Technology Research and Development, vol. 50, pp. 5-22, 2002.

[14] M. Baker and K. Lund, "Promoting reflective interactions in a CSCL environment," Journal of Computer Assisted Learning, vol. 13, pp. 175-193, 1997.

[15] J. Robertson, J. Good, and H. Pain, "BetterBlether: The design and evaluation of a discussion tool for education," International Journal of Artificial Intelligence in Education, vol. 9, pp. 219-236, 1998.

[16] A. Soller, B. Goodman, F. Linton, and R. Gaimari, "Promoting effective peer interaction in an intelligent collaborative learning system," Intelligent Tutoring Systems, 1998, pp. 186-195.

[17] A. W. Lazonder, P. Wilhelm, and S. A. W. Ootes, "Using sentence openers to foster student interaction in computer-mediated learning environments," Computers \& Education, vol. 41, pp. 291-308, 2003.

[18] T. Yiong-Hwee and D. Churchill, "Using Sentence Openers to Support Students' Argumentation in an Online Learning Environment," Educational Media International, vol. 44, pp. 207-218, 2007.

[19] S. Mcalister, A. Ravenscroft, and E. Scanlon, "Combining interaction and context design to support collaborative argumentation using a tool for synchronous CMC," Journal of Computer Assisted Learning, vol 20, pp. 194-204, 2004.

[20] L. Hirsch, M. Saeedi, J. Cornillon, and L. Litosseliti, "A structured dialogue tool for argumentative learning," Journal of Computer Assisted Learning, vol. 20, pp. 72-80, 2004.

[21] S. E. Toulmin, The Uses of Argument, Cambridge University Press, 2003.

[22] K. Stegmann, C. Wecker, A. Weinberger, and F. Fischer, "Collaborative argumentation and cognitive processing: An empirical study in a computer-supported collaborative learning environment," in Proc. the 8th iternational conference on Computer supported collaborative learning, 2007, pp. 662-671.

[23] O. Noroozi, A. Weinberger, H. J. A. Biemans, M. Mulder, and M Chizari, "Facilitating Argumentative Knowledge Construction through a Transactive Discussion Script in CSCL," Computers \& Education, 2012.

[24] D. Newman, C. Johnson, B. Webb, and C. Cochrane, "Evaluating the quality of learning in computer supported co-operative learning," Journal of the American Society for Information Science, vol. 48, pp. 484-495, 1997.

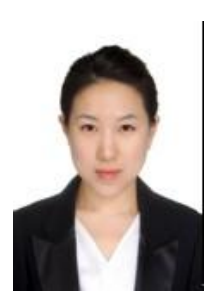

Hyejeong Lee majored in Chinese language and culture in Hanyang University, Korea and graduated in February of 2008. Her research interests are instructional design, computer-supported collaborative learning, distance education, language education. Ms. Lee is currently a research member of Brain Korea 21.

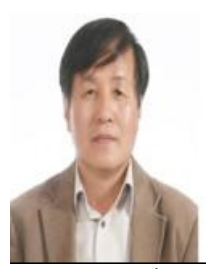

Dongsik Kim majored in educational technology and received a Ph.D degree in April of 1990 from Florida State University, Tallahassee, FL, USA. He is in Hanyang University from 1993 as a PROFESSOR in department of educational technology. His research interests are instructional design , CSCL, e-learning, multimedia learning, cognitive load theory. He has published "Development of interactive e-learning plotform: $2^{\text {nd }}$ generation interface for Web 2.0" (Proceedings of the $26^{\text {th }}$ Annual conference of JSET, 2010), "The effects of Scaffolds for argumentative interaction in collaborative learning" (Cyber change: learning in our connected world: 2010 AECT International convention, 2010), and "The effects of the coordination support on shared mental models and coordinated action" (British Journal of Educational Technology, 2008) and so on 